\title{
Migración, transnacionalización y cultura
}

Elsa Ramos

Recibido: 10/07/2013 - Aceptado: 16/09/2013

\begin{abstract}
Resumen
El presente artículo es resultado de la investigación "La transnacionalización de la sociedad salvadoreña, producto de las migraciones", cuyo objetivo principal era determinar elementos de dicha situación. Es un estudio histórico y etnográfico. El método utilizado fue cualitativo, con entrevistas semi estructuradas a personas de los municipios estudiados, sesiones de fotografía y otros. De los resultados principales que se obtuvieron se puede mencionar la expansión a lugares remotos de las compañías privadas de cable y TV, agencias de transferencias, el grafiti y otros.
\end{abstract}

\section{Palabras clave}

Geografía Humana, cultura, diferenciación cultural, sistemas culturales, etnología, inmigrantes.

\section{Introducción}

En la actualidad, la sociedad mundial está inmersa en el llamado proceso de globalización, que ha posibilitado la interrelación e interdependencia económica, sociopolítica y cultural. En ese sentido, y desde el punto de vista económico, se ha creado un mercado global en donde hay una libertad casi absoluta de los capitales financieros y de las mercancías, mas no del capital humano poco cualificado.

Conjuntamente a la globalización se ha desarrollado un nuevo modelo económico dentro del sistema capitalista, que es el neoliberalismo. Este considera que la esfera económica de las sociedades no debe de tener ninguna injerencia del Estado, pues las leyes del mercado bastan para regular dicha esfera.

\section{Abstract}

This article is the result of the research "The transnationalization of Salvadoran society, the product of migration", whose main objective is to identify elements of transnationalization. It is a historical and ethnographic study. The method used was qualitative, semi-structured interviews with mayors in the municipalities studied, photo shoots and more. From the main results obtained it is observed the expansion of cable TV private companies and money transfers agencies, in remote and rural areas in the country, graffiti and other phenonomena.

\section{Keywords}

Human geography, culture, cultural differentiation, cultural systems, ethnology, immigrants.
Lo anterior ha dado como resultado que en las sociedades actuales se generen grandes asimetrías económicas entre los diferentes grupos y clases sociales. Así, los grupos más desfavorecidos de la sociedad ven permanentemente desmejorada su calidad de vida. Esa situación es más evidente en las llamadas economías en desarrollo, como lo es la de El Salvador. Lo anteriormente mencionado ha promovido que grandes grupos de población busquen una salida a la precaria situación económica en que están viviendo. La solución la han encontrado en las migraciones Sur-Sur y las Sur-Norte.

En el caso específico de El Salvador, el flujo masivo de connacionales migrando fuera del país se empezó a observar a finales de la década de los años setenta (PNUD, 2005); pero no como producto de la globalización y el neoliberalismo, 
sino por la guerra civil que se estaba desarrollando entre 1980 y 1992. En décadas posteriores, y en especial después de firmados los Acuerdos de Paz, los salvadoreños iniciaron sus procesos migratorios como producto de la aplicación de medidas neoliberales en el país. Cabe aclarar que las causas de la migración en el país no son solamente de índole económica, sino que también están generadas por los desastres naturales que han azotado al país, la reunificación familiar en el extranjero y por la violencia social y criminal.

Igual que en otros países de altos índices migratorios, en El Salvador las migraciones han transformado profundamente a la sociedad. Así, en el Informe sobre Desarrollo Humano de El Salvador 2005 se afirma que ya no somos los mismos, que se ha estado pensando y planificando para un El Salvador que ya no existe por el impacto de las migraciones.

\section{Metodología}

El estudio se realizó bajo la modalidad de investigación cualitativa que, de acuerdo con Hernández S. R.; Fernández, C. C. y Baptista, L. P. (2006), se fundamenta más en un proceso inductivo (explorar y describir), para luego generar perspectivas teóricas. Se parte de lo particular a lo general.

Las técnicas utilizadas fueron las entrevistas semiestructuradas a los alcaldes o funcionarios; los encargados de las casas de la cultura de nueve de los diez municipios que reciben más remesas en el país, de acuerdo con el mapa de las migraciones (PNUD, 2011); y de dos municipios emblemáticos en el tema migratorio: Intipucá y Santa Rosa de Lima. Se realizaron recorridos de observación en los cascos de dichos municipios, así como de algunos cantones de estos. Los recorridos fueron, también, utilizados para la realización de registros fotográficos de aquellos elementos que se consideraron como representativos de la transnacionalización cultural.

\section{Algunos mecanismos de la transnacionalización}

\footnotetext{
- La economía de las migraciones

- Redes sociales de la migración

- Transporte

- Telecomunicaciones
}

- Turismo nostálgico

- Remesas sociales

- Medios de comunicación social

La mayoría de los estudios realizados en el país, en relación con el tema migratorio, se han enfocado principalmente en el área económica, y en especial sobre remesas (García y Palacios, s/f; Cemla, 2009), cuestión que hasta cierto punto se aclara porque, de acuerdo con el Banco Central de Reserva (2013), para el año 2012 se recibieron 3.910 .9 millones de dólares en concepto de remesas, las cuales contribuyeron con un $16,4 \%$ al producto interno bruto del país.

Sin embargo, el impacto de las migraciones no se reduce al ámbito económico, sino que también se está reflejando en la esfera social y cultural. Así, los cambios culturales (Rodríguez, s/f) se dejan sentir en todos los niveles de la vida social, en la cotidianeidad misma de las relaciones sociales, transformando hábitos, concepciones, gustos y aspiraciones.

Para entender en alguna medida esos cambios y transformaciones sociales y culturales, García Canclini (2001) ofrece la categoría de análisis Hibridación cultural, entendida como un término de traducción entre mestizaje, sincretismo y fusión de los otros vocablos empleados para designar mezclas particulares; es decir, se está haciendo referencia a un término o concepto polisintético que abre varios caminos de análisis para emprender el estudio de las transformaciones culturales de la sociedad actual.

El Salvador cuenta con apenas $21.040 .79 \mathrm{~km}^{2}$ y 5.744 .113 habitantes. De acuerdo con el VI Censo de Población de 2007 (Digestyc, 2008) ha experimentado transformaciones socioculturales debido a las migraciones. Así, el proceso masivo de migración internacional ya tiene más de tres décadas de desarrollo. En ese período, la cantidad de salvadoreños migrantes alrededor del mundo ha alcanzado la cifra de 2.950.156 (PNUD; 2011); de estos, solo en los Estados Unidos viven 2.587.767.

Se debe señalar que los migrantes salvadoreños no solo envían remesas monetarias, sino que hay un amplio intercambio de elementos de tipo simbólico, costumbres, nuevos gustos y aficiones, transmitidos a través de las llamadas remesas sociales. Reafirmado lo anterior, Asakura (2006) menciona que estas, abarcan las ideas, comportamientos, identidades y capital social, que fluyen desde el lugar de destino hacia el de origen, y viceversa. 
Otro elemento que está íntimamente relacionado con las migraciones internacionales es el crecimiento del intercambio comunicacional a través de los modernos sistemas de comunicación a través de internet (redes sociales, Skype y otras); las radios y periódicos digitales; las empresas de televisión por cable en el país, que transmiten constantemente noticias para los que se quedan y para los que se van. Es decir, las comunicaciones digitales y los medios de comunicación social están jugando un papel relevante en las transformaciones culturales que se observan constantemente en la sociedad salvadoreña de nuestros días.

En los últimos años, se ha estado desarrollando el llamado turismo nostálgico por aquellos salvadoreños que, una vez resuelta su estancia legal en los países de destino, visitan regularmente el país en ocasión de las fiestas patronales de sus respectivos pueblos, en la época de Semana Santa o la de las fiestas de Navidad y Año Nuevo. Durante las fiestas patronales de los municipios estudiados, de acuerdo con el testimonio de algunos alcaldes entrevistados, se promueve la celebración del "Día del Migrante", en donde se les ofrecen banquetes con platos tradicionales, desfiles y elección de las reinas de las colonias, la reina de las fiestas patronales, así como la reina de los migrantes. Esta generalmente viaja desde la comunidad de destino en los Estados Unidos. Lo anterior de alguna forma está contribuyendo a la preservación de las costumbres y tradiciones, pero, a la vez, se introducen nuevos elementos culturales de la sociedad de recepción.

Uno de los municipios iconos de la migración salvadoreña es Intipucá, en donde se pueden observar diferentes elementos constitutivos de la transnacionalización. Entre ellos se puede mencionar la existencia de señalética en inglés y español; calles que han sido nombradas en honor a personajes de la historia de Estados Unidos, como la calle George Washington; la calle William Walker (ex embajador de Estados Unidos en El Salvador); la nominación de una calle cercana a la alcaldía municipal como calle del "Hermano Lejano"; la construcción de un monumento al migrante en el parque municipal (ver figura 1); la celebración de los 45 años del inicio de la migración en el pueblo, en el año de 1967, como se muestra en la figura 2. El dato anterior fue ofrecido por el alcalde de Intipucá, señor Enrique Méndez, en una entrevista semiestructurada.

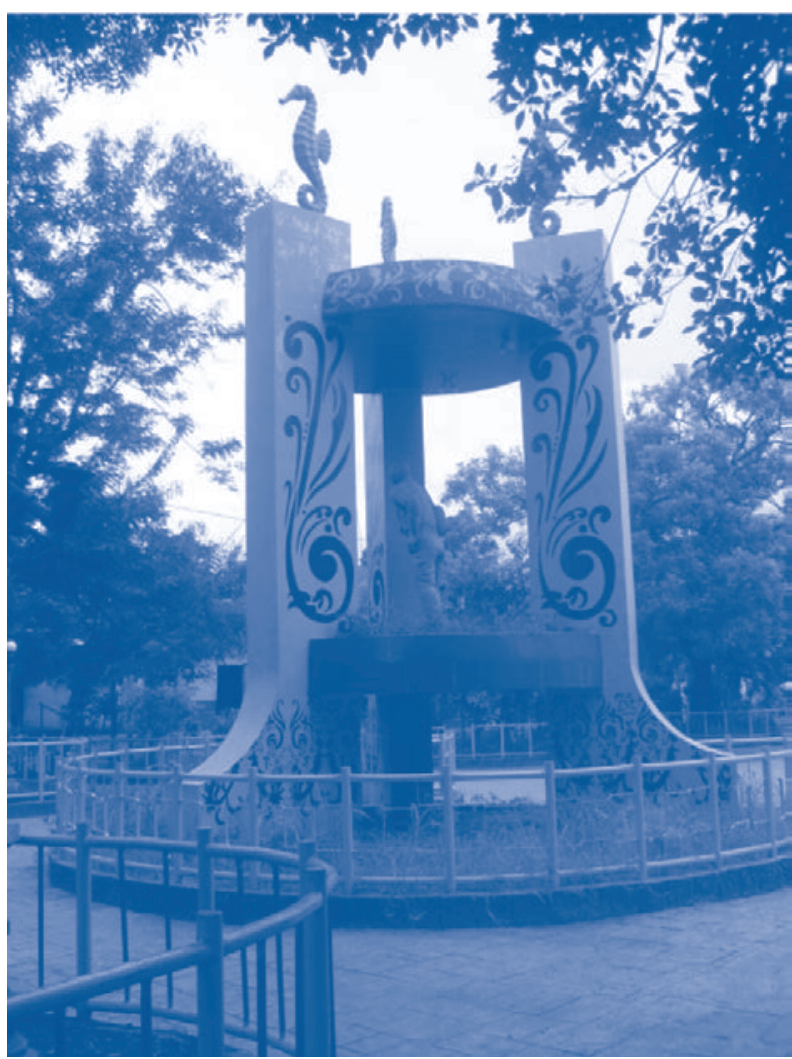

Figura 1. Parque de los migrantes.

Foto tomada por Elsa Ramos

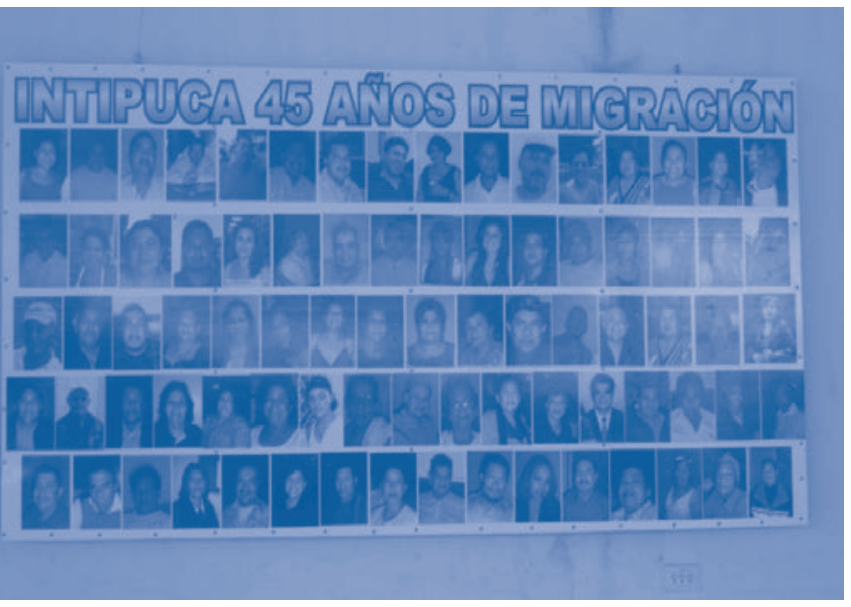

Figura 2. Intipucá, icono de las migraciones de El Salvador. Foto tomada por Elsa Ramos

En muchos hogares en donde uno o varios de sus miembros han migrado, se puede observar en los corredores de las casas la exhibición de la bandera salvadoreña junto a la estadounidense, como se observa en la figura 3. 


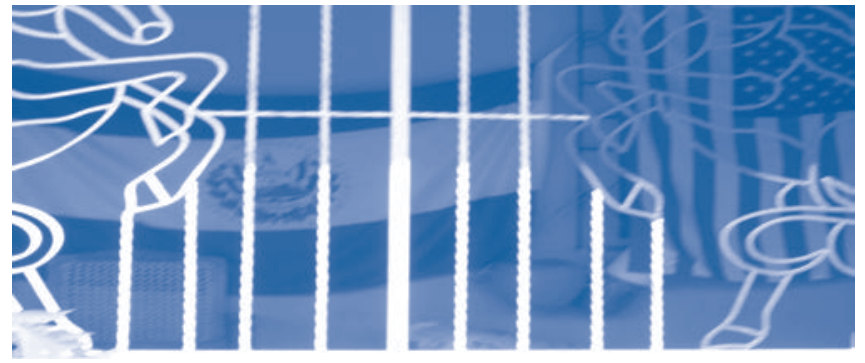

Figura 3. Símbolo: la madre patria y la sociedad de oportunidades. Foto tomada por Elsa Ramos

Todo lo anteriormente expresado lleva a inferir que la sociedad salvadoreña, como resultado de las migraciones, paulatinamente se está transformado en una sociedad transnacional, entendiéndose esta como una sociedad cuyas fronteras físicas son permeables, en donde gran cantidad de sus ciudadanos no solo adjudican su pertenencia a una patria, sino que tienen prácticas culturales de su sociedad de destino, incluyendo las adquiridas por el intercambio cultural con personas migrantes de otros países y que residen en la misma sociedad de recepción.

\section{Conclusión}

En El Salvador, como en muchos otros países en donde aún priva una concepción decimonónica (nacionalista, excluyente) de la cultura, reflexionar sobre las transformaciones por las que está atravesando ponen en alerta roja, bajo el supuesto de que la identidad nacional, los valores, las costumbres y las tradiciones se contaminarán, perderán su pureza e inclusive desaparecerán. Los procesos históricos han demostrado que no hay culturas puras, que parte de las características de estas es su capacidad de transformación según las necesidades de la sociedad.

De acuerdo con García Canclini (2001), los cambios culturales actuales no se pueden comprender y estudiar desde los parámetros de la aculturación, el mestizaje, el sincretismo y otros, sino bajo una perspectiva más amplia en donde se fusionan todos estos elementos. No hay límites prestablecidos, es el investigador el que debe realizar las propuestas de análisi

\section{Referencias}

Asakura, Hiroko (2006). Experiencias en espiral. Remesas sociales y servicios de salud en una comunidad mixteca. En: http://www.gimtrap.org/files/356.pdf

Banco Central de Reserva (2013). Comunicado de Prensa $N^{\circ}$ 1/2013. US\$3.910.9 millones en remesas familiares ingresaron en 2012. En: http://www.bcr.gob.sv/bcrsite/uploaded/content/category/2039438598.pdf

Cemla (2009). Remesas internacionales en El Salvador. En: http://www.cemla-remesas.org/informes/informeelsalvador.pdf

García, Xiomara de; Palacios, Morena de (s/f). Características de los remitentes de remesas familiares desde Estados Unidos. En: http://www.pnud.org.sv/migraciones/static/biblioteca/07_BCR_Garcia_Xiomara_caracterisiticas_de_los_remitentes.pdf

García Canclini, Néstor (2001). Culturas híbridas. Estrategias para entrar y salir de la modernidad. Nueva edición. Argentina, Paidós.

Hernández, S. R.; Fernández, C. C. y Baptista, L. P. (2006). Metodología de la investigación. México, McGraw-Hill Interamericana.

Rodríguez Herrera (s/f), América. La migración internacional, su impacto en la cultura de los sectores campesinos. En: http://ca2020.fiu.edu/Workshops/Salvador_Workshop/Am\%C3\%A9ricaRodr\%C3\%ADguezHerrera.html

PNUD (2005). "Informe sobre Desarrollo Humano El Salvador. Una mirada al nuevo nosotros. El impacto de las migraciones".

PNUD, Cancillería y UCA (2011). "Mapa de las Migraciones Salvadoreñas". En: http://www.pnud.org.sv/migraciones/content/view/58/131/

Digestyc (2008). VI Censo de Población y V de vivienda 2007. En: http://www.digestyc.gob.sv/index.php/novedades/publicaciones/category/27-censo-de-poblaciony-vivienda-2007.html 